\title{
Serum magnesium levels in relation to metabolic syndrome: A national population-based cross- sectional study from Jordan
}

Nuha Shugaa Addin ( $\sim$ dr.nuha.dn@gmail.com )

Department of Community Medicine, Public Health and Family Medicine, Faculty of Medicine, Jordan University of Science \& Technology, Irbid 22110, Jordan https://orcid.org/0000-0002-1499-9885

\section{Anwar Batieha}

Department of Community Medicine, Public Health and Family Medicine, Faculty of Medicine, Jordan University of Science \& Technology, Irbid 22110, Jordan

\section{Yousef Khader}

Department of Community Medicine, Public Health and Family Medicine, Faculty of Medicine, Jordan University of Science \& Technology, Irbid 22110, Jordan

\section{Hashim Jaddou}

Department of Community Medicine, Public Health and Family Medicine, Faculty of Medicine, Jordan University of Science \& Technology, Irbid 22110, Jordan

\section{Mohammed El-Khateeb}

National Center for Diabetes, Endocrinology and Genetics, P.O. Box 13165, Amman 11942, Jordan

\section{Kamel Ajlouni}

National Center for Diabetes, Endocrinology and Genetics, P.O. Box 13165, Amman 11942, Jordan

\section{Research Article}

Keywords: Metabolic syndrome, Obesity, Hypomagnesemia, Jordanian population

Posted Date: May 26th, 2021

DOl: https://doi.org/10.21203/rs.3.rs-543476/v1

License: (c) (i) This work is licensed under a Creative Commons Attribution 4.0 International License.

Read Full License 


\section{Abstract \\ Background/Aims:}

Individuals with metabolic syndrome are at higher risk to develop cardiovascular disease, diabetes type 2, and certain types of cancers such as pancreatic, liver, and colorectal cancers. Studies suggest a potential association between hypomagnesemia and metabolic syndrome with conflicting results. The present study aims to estimate the prevalence of metabolic syndrome and its components in Jordan and to further explore the association between low magnesium levels and metabolic syndrome and its components.

\section{Methods}

Data were derived from the national population-based household survey conducted in Jordan in 2009. The study was multipurpose and collected a wide array of data including interview data, anthropometric measurements, and laboratory data. The present report deals, exclusively, with subjects aged $\geq 20$ years. There was a total of 4,520 subjects ( 1113 men and 3407 women).

\section{Results}

We found alarmingly high prevalence rates of metabolic syndrome and its components defined by IDF (international diabetic federation) criteria (39.8\%) with the highest burden being among women (40.7\% in women and $37.4 \%$ in men). Among metabolic syndrome components, central obesity and low HDL were the most commonly occurring components of metabolic syndrome (62.6\% and $65.5 \%$, respectively). We observed a significant inverse association between serum magnesium levels and metabolic syndrome after adjusting for age $(O R=1.57, p$ value $=0.048)$. Among metabolic syndrome components, low serum magnesium levels were significantly associated with low serum HDL levels $(O R=2.15, p$ value $=0.001)$.

\section{Conclusion}

Metabolic syndrome prevalence in Jordan is considerably high. Our findings suggest that serum magnesium levels are inversely associated with metabolic syndrome.

\section{Introduction}

The epidemic growth of non-communicable diseases (NCDs) leading to an increased risk of morbidity and mortality constitutes a major global health challenge. The Global Burden of Disease 2016 study (GBD2016) showed that death from non-communicable diseases represented $72.3 \%$ of deaths in 2016 (1). Adoption of an unhealthy lifestyle in the form of physical inactivity, unhealthy diet, and tobacco use has led to the increasing burden of NCDs (2). Metabolic risk factors, on the other hand, manifested by 
raised blood pressure, central obesity, hyperglycemia, and hyperlipidemia comprising what is known as metabolic syndrome are incriminated in the rising incidence of NCDs (3).

The worldwide prevalence of metabolic syndrome is on the rise and it has become an essential public health problem among numerous developed and developing counties. The prevalence of metabolic syndrome varies between 10 to $85 \%$ according to the definition used, study design, sample selection, ethnicity, and the age and gender structure of the population. The IDF, on the other hand, estimates that one-quarter of the world's population has metabolic syndrome (4). Metabolic syndrome is a multifactorial condition that stems from the interactions between metabolic, environmental, and genetic factors (5). Reducing the burden of metabolic syndrome is of great importance for the prevention of major noncommunicable diseases, such as cardiovascular disease and diabetes type 2 . Evidence has shown that individual metabolic syndrome components were independent risk factors for cardiovascular disease (6), and their combination augments the rates and severity of its development producing a spectrum of vascular and cardiac diseases.

Magnesium is an essential mineral for the human body being the forth abundant cation after calcium, potassium, and sodium and the second most abundant intracellular cation after potassium (7). It has several vital functions, namely muscle and cardiac contraction, neuromuscular conduction, and glycemic control. Moreover, magnesium is regarded as a cofactor for more than 300 enzymes. In addition, it plays a fundamental role in energy production, active transmembrane transport of ions, synthesis of nuclear material, and bone development (8). Magnesium hemostasis is maintained by the balance between intake, absorption, and excretion which is regulated by the intestines, the bones, and the kidneys (9). Approximately $60 \%$ of the total body magnesium is found in bone and $20 \%$ is localized to muscles, while $20 \%$ is found in other tissues of the body. Only $1 \%$ is present in the extracellular fluid compartments, of which $0.3 \%$ is in the serum (10).

Several non-communicable diseases have been associated with alterations in the levels of some minerals, among them low magnesium levels. Evidence has suggested that magnesium depletion may play an essential role in the pathophysiology of diabetes mellitus, hypertension, obesity, and dyslipidemia $(6,11-13)$. In this context, there is a biological plausibility to associate hypomagnesemia with metabolic syndrome. Studies suggest potential benefits of magnesium in preventing the development of metabolic syndrome and its components, although the literature is not consistent in this regard. Some studies (1416) demonstrated an inverse association between magnesium levels and metabolic syndrome, whereas others could not establish a significant association (17-19). Surprisingly, a case-control study has proposed that higher levels of magnesium were associated with an increased risk of developing metabolic syndrome (20).

Given the worldwide increase in the prevalence of metabolic syndrome and its major medical and social burden, efforts have been made to shed light on the possible mechanisms involved in its pathogenesis so as to develop strategies focused on its prevention and management. Therefore, the aims of this study were to estimate the prevalence of metabolic syndrome among Jordanians and to investigate the 
association between low serum magnesium levels and metabolic syndrome and its components in a national population-based cross-sectional study.

\section{Methods}

\subsection{Sample selection}

This study derived its data from the national population-based household survey from the 12 governorates of Jordan 2009 (21). These 12 governorates belong to the three regions of the country, namely, the North, Middle, and South. The Sample was selected using a complex multistage sampling technique taking into consideration the geographic distribution of the population as well as the urbanrural residence. Because the study procedures (anthropometric measures, drawing blood samples, etc.) required a clinical setting and the population is covered by extensive networks of health centers, the selection of households was heath center-oriented. The health director in each governorate was contacted and asked to select at least 2 health centers in the governorate which he believes to be representative and at the same time large enough to provide the space for the study team ( 25 members), participants, and equipment. A total of 31 health centers distributed throughout Jordan were selected and the people served by these centers were targeted. A systematic sample of households was selected from the catchment area of each selected health center.

A team of two (one man and one woman) went door-to-door selecting every third to sixth household, depending on the population density. The team invited all those aged $\geq 7$ years in the selected households to report to the health center the next day after explaining the purpose of the study to them. Participants were asked to fast and not to take their medication on that day, but to bring their medications to the health center. To encourage participation, the team worked on weekends and holidays, and provided free transportation for those who requested it. Of the 9,000 subjects invited to participate 5,640 responded. The overall response rate was $63 \%$ being $36 \%$ in men and $90 \%$ in women. The main reason behind the lower response rate in men was employment, often far from their place of residence. The unemployment rate in women is much higher than in men, which makes women more available for participation.

\subsection{Data collection}

The study was multipurpose covering several aspects of health care for non-communicable diseases through the collection of a wide array of data, including interview data, anthropometric measurements, and laboratory data.

\section{- Interview data}

Data collection took place between 1 st of July and 30th of November, 2009. Participants attended the health centers in the morning ( $8-11 \mathrm{am}$ ) with a minimum 10 hours fasting time. The study included a total of 5640 subjects aged between 7 and 90 years. A pilot tested structured questionnaire was prepared 
and administered by well-trained interviewers to collect relevant data on sociodemographic factors, risk factors for cardiovascular disease, style of dress and sun exposure, morbidity, quality of life and health services use, among others. The present study deals, exclusively, with participants $\geq 20$ years of age. There was a total of 4,520 subjects ( 1113 men and 3407 women).

\section{- Anthropometric measurements}

Anthropometric measurements including weight, height, waist, and hip circumferences were measured with the subjects wearing light clothing and no shoes. Height and weight were determined to the nearest $0.1 \mathrm{~cm}$. Waist circumference was measured to the nearest centimeter using non-stretchable tailors measuring tape at the narrowest point between the iliac crest and rib cage during minimal respiration. Readings of systolic (SBP) and diastolic blood pressure (DBP) were taken in duplicates with the subject seated and the arm at heart level, after at least 5 minutes of rest, using standardized mercury sphygmomanometer with appropriate arm cuff length. The mean of these two determinations was used to express the individual's systolic and diastolic blood pressures.

\section{- Laboratory tests}

For all biochemical measurements, two sets of fasting blood samples were drawn from a cannula inserted into the antecubital vein into sodium fluoride potassium oxalate tubes for glucose and lithium heparin vacuum tubes for lipids. Samples were centrifuged at $3000 \mathrm{rpm}$ for $10 \mathrm{~min}$ within 1 hour at the survey site, and plasma was transferred to separate labeled tubes and transferred immediately in cold boxes filled with ice to the central laboratory of the National Center for diabetes and endocrinology. All biochemical measurements were carried out by the same team of laboratory technicians and the same method throughout the study period. Triglycerides values were obtained on COBAS INTEGRA 700 with the cassette COBAS INTEGRA Triglycerides using enzymatic, colorimetric method (GPO/PAP) with glycerol phosphate oxidase and 4-aminophenazone. Total cholesterol was analyzed using enzymatic, colorimetric method with COBAS INTEGRA Cholesterol Gen.2. HDL cholesterol and LDL cholesterol values were obtained on COBAS INTEGRA 700 using homogeneous enzymatic colorimetric assay. Magnesium was measured by "Colorimetric Endpoint Method" using Roche/Cobas Integra 800 automated system. Other laboratory analysis was also performed for several blood constituents, but it is not described here because they are irrelevant to the current report.

\subsection{Definition of variables}

Metabolic syndrome was defined according to IDF definition (22) which entails the presence of central obesity (waist circumference $>94 \mathrm{~cm}$ in men and $>80 \mathrm{~cm}$ in women) along with two or more of the following: Raised triglycerides $>150 \mathrm{mg} / \mathrm{dl}$ or specific treatment for the lipid abnormality, blood glucose greater than $100 \mathrm{mg} / \mathrm{dl}$ or diagnosed diabetes, low HDL-Cholesterol: HDL-C $<40 \mathrm{mg} / \mathrm{dl}$ in men and $<50$ $\mathrm{mg} / \mathrm{dl}$ in women, or blood pressure $\geq 130 / 85 \mathrm{mmHg}$ or drug treatment for hypertension. As for magnesium, our operational definition of hypomagnesemia was the occurrence of serum magnesium level below $1.82 \mathrm{mg} / \mathrm{dl}(23)$. 


\subsection{Ethical considerations}

Ethical approval was obtained from the Ethical Committee for Research on Humans of the National Center for Diabetes, Endocrinology and Genetics, and it was supported by the Ministry of Higher Education. An informed consent was obtained from the responded individuals and their guardians in case the participants were children. Physical examinations and interviews were carried out by well-trained personnel. All study procedures were performed free of charge for participants. The privacy of participants was respected. Identifying information was kept strictly confidential and the data were used only for scientific purposes. The examination results were disseminated to each participant privately and in case there were abnormal findings, they would be referred to their doctors for necessary intervention.

\subsection{Data management and statistical analysis}

Data were analyzed using the Statistical Package for Social Science (SPSS version 21). The continuous data were expressed as mean and standard deviation (SD), and the category data were expressed in percentage. Prevalence rates of metabolic syndrome and its components were obtained and reported separately for each gender. The overall prevalence of hypomagnesemia was calculated and also in the subgroups defined by relevant variables. The bivariate association between low magnesium levels and a number of variables was assessed for statistical significance using the chi-square test. Multivariate logistic regression models were fit to demonstrate the association of hypomagnesemia with metabolic syndrome and its components while simultaneously controlling for age as a potential confounder. For this purpose, magnesium status was dichotomized, using $1.82 \mathrm{mg}$ as the cutoff point, and entered the model as the dependent variable. All other relevant variables were treated as independent variables. Gender was removed from the logistic regression models as it was insignificant in the bivariate analysis and remained insignificant in the models. Magnesium was also analyzed as a continuous variable using linear regression models while controlling for age as a potential confounder. A P-value of $<0.05$ was considered statistically significant.

\section{Results}

\subsection{Socio-demographic Characteristics}

Table 1 shows the sociodemographic characteristics of the study population. This study included 4520 participants [1113 $(24.6 \%)$ men and $3407(75.4 \%)$ women] aged 20 years or more. About $27.8 \%$ of them were between $40-49$ years old. The majority of participants $(79.9 \%)$ were married while $12.9 \%$ were single. Current smokers constituted $15.1 \%$ of the study participants while $79.9 \%$ were non-smokers.

\subsection{Anthropometric and Clinical Characteristics}

Table 2 shows the mean anthropometric and clinical characteristics for Jordanians in 2009. The mean (SD) of BMI was $29.9(5.9) \mathrm{kg} / \mathrm{m}^{2}$. The mean (SD) of waist circumference was 87.6 (14.5) cm. The mean (SD) for systolic blood pressure was 122.4 (17.3) $\mathrm{mmHg}$ while for diastolic blood pressure was 79.0 
(10.3) $\mathrm{mmHg}$. The mean (SD) of fasting blood sugar, $\mathrm{HDL}$, triglycerides, and Magnesium were 102.6 (50.6) $\mathrm{mg} / \mathrm{dl}, 43.9$ (13.6) mg/dl, 175.9 (123.5) mg/dl, and $2.4(0.4) \mathrm{mg} / \mathrm{dl}$, respectively.

Table 2

Anthropometric and clinical characteristics of the study participants

\begin{tabular}{|l|}
\hline Variable NO.(\%) \\
\hline Age (year) \\
\hline $20-29827(18.3)$ \\
$30-391202(26.6)$ \\
$40-491237(27.8)$ \\
$50-59702(15.5)$ \\
$\geq 60502$ (12.2) \\
\hline Gender \\
\hline Men 1113 (24.6) \\
Women 3407 (75.4) \\
\hline Marital status \\
\hline Single 585 (12.9) \\
Married 3613 (79.9) \\
Divorced 67 (1.5) \\
Widow 255 (5.6) \\
\hline Smoking status \\
\hline Current 684 (15.1) \\
Past 215 (4.8) \\
Never 4609 (79.9) \\
\hline (N = 4520), Jordan 2009 \\
\hline
\end{tabular}

\subsection{Prevalence rates of metabolic syndrome and its components}

Table 3 shows the gender-specific rates of metabolic syndrome and its individual components of the study participants, using IDF definition. The prevalence of metabolic syndrome was $39.8 \%$ being higher in women $(40.7 \%)$ than in men (37.4\%); p-value (0.041). The prevalence of central obesity was $62.6 \%(51.3 \%$ among men and $66.5 \%$ among women, $p=0.000)$. The prevalence of triglycerides was $49.2 \%$ being 
higher in men (63.0\%) than in women (44.7\%); $p$ value (0.000). Similarly, the prevalence of low HDL was higher in men $(69.6 \%)$ than in women $(64.0 \%)$ with an overall prevalence of $65.5 \%$; $p$ value $(0.000)$. The prevalence of hypertension was $41.0 \%$ (53.1\% in men and $37.0 \%$ in women, $p=0.000)$. The prevalence of hyperglycemia was $29.6 \%$ ( $38.4 \%$ in men and $26.8 \%$ in women, $p=0.000$ ).

Table 3

The gender-specific rates of metabolic syndrome and its individualized components in Jordan, using the IDF definition, Jordan 2009

\begin{tabular}{|l|}
\hline Variable Mean (SD) \\
\hline Body mass index $\left(\mathrm{kg} / \mathrm{m}^{2}\right) 29.9(5.9)$ \\
Waist circumference $(\mathrm{cm}) 87.6(14.5)$ \\
Systolic blood pressure $(\mathrm{mmHg}) 122.4(17.3)$ \\
Diastolic blood pressure (mmHg) $79.0(10.3)$ \\
Fasting blood sugar (mg/dl) $102.6(50.6)$ \\
HDL (mg/dl) $43.9(13.6)$ \\
Triglyceride (mg/dl) $175.9(123.5)$ \\
Serum magnesium (mg/dl) $2.4(0.4)$ \\
\hline
\end{tabular}

\subsection{Prevalence of hypomagnesemia in the study population}

The overall prevalence of hypomagnesemia in the population was $2.7 \%(n=120)$. The prevalence rates of hypomagnesemia by sociodemographic characteristics are shown in Table 4. Participants older than 60 years old were significantly more likely to have low magnesium levels $(5.4 \%)$ compared to younger age groups $(p=0.000)$. 
Table 4

Prevalence of hypomagnesemia, overall and by Sociodemographic characteristics of the study participants, Jordan 2009

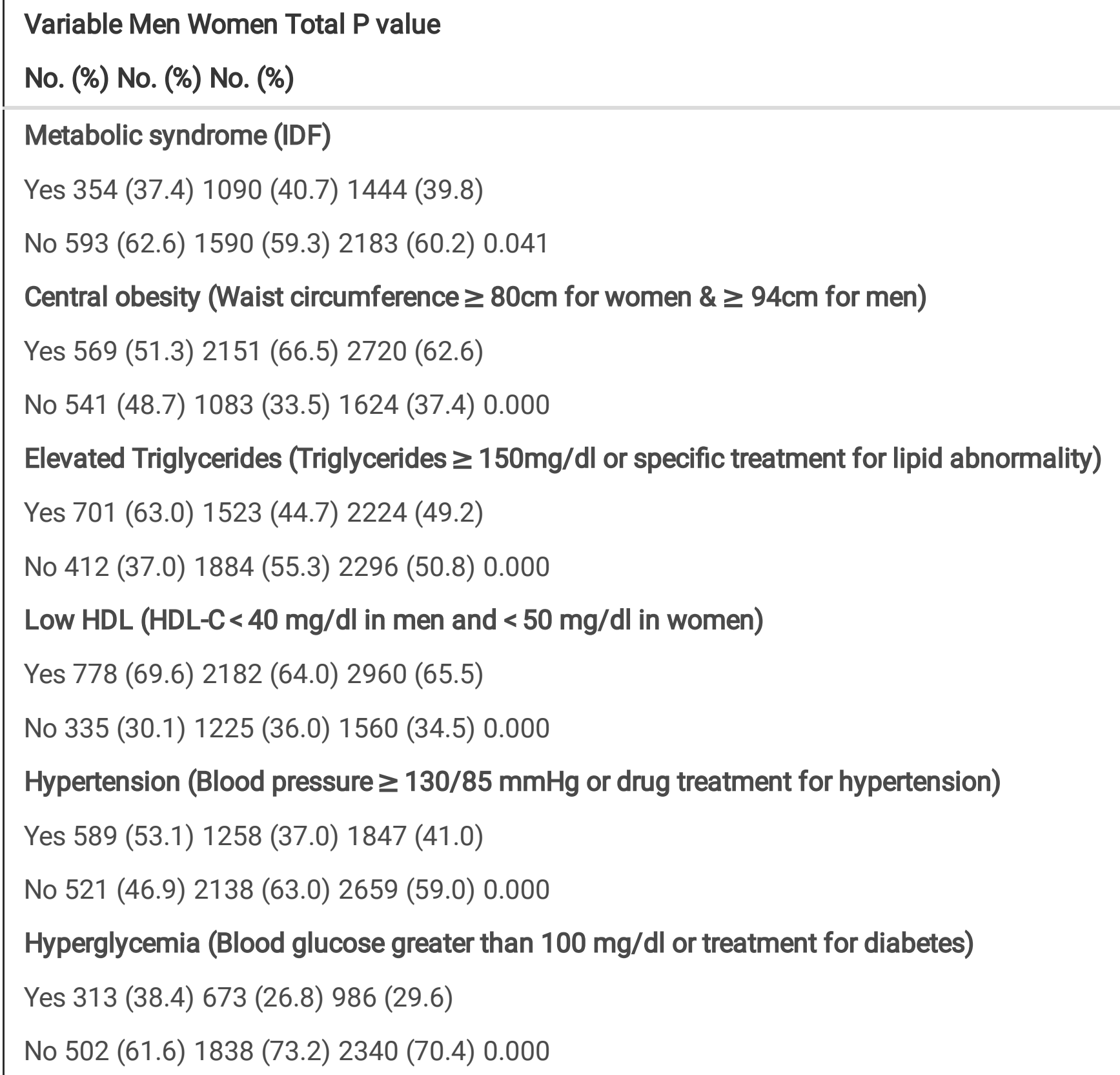

Table 5 shows the prevalence of hypomagnesemia by metabolic syndrome and its components. Subjects with metabolic syndrome were significantly more likely to have low magnesium levels (4.3\%) than those without the condition $(p=0.000)$. Central obesity was significantly associated with low magnesium levels $(2.8 \%)$ in comparison to non-obese subjects $(p=0.041)$. Subjects with low HDL were significantly more likely to have a high prevalence of hypomagnesemia (3.3\%) compared to those with normal HDL levels $(p=0.000)$. Hypertensive subjects were significantly more likely to have low magnesium levels $(3.6 \%)$ in comparison with non-hypertensive subjects $(p=0.001)$. The prevalence of hypomagnesemia is significantly higher among hyperglycemic subjects (5.1\%) compared to subjects with normal blood glucose $(p=0.002)$. 
Table 5

Prevalence of hypomagnesemia by metabolic syndrome and its individualized components, using IDF definition, Jordan 2009

\begin{tabular}{|c|}
\hline $\begin{array}{l}\text { Variable Serum magnesium levels, } \mathrm{mg} / \mathrm{dl} \\
>1.82<=1.82 \mathrm{P} \text { value } \\
\text { No. }(\%) \text { No. }(\%)\end{array}$ \\
\hline Total $4400(97.3) 120(2.7)$ \\
\hline Age (years) \\
\hline $20-29809(97.8) 18(2.2)$ \\
\hline 30-39 1174 (97.9) 28 (2.3) \\
\hline $40-491220$ (98.6) 17 (1.4) 0.000 \\
\hline $50-59675(96.6) 27(3.8)$ \\
\hline$\geq 60522$ (94.6) 30 (5.4) \\
\hline Gender \\
\hline Men 1091 (98.0) 22 (2.0) \\
\hline Women 3309 (97.1) 98 (2.9) 0.062 \\
\hline Marital status \\
\hline Single 574 (98.1) 11 (1.9) \\
\hline Married 3518 (97.4) 95 (2.6) \\
\hline Divorced 66 (95.5) 1 (1.5) 0.055 \\
\hline Widow 242 (94.9) 13 (5.1) \\
\hline Smoking status \\
\hline Current 674 (98.5) 10 (1.5) \\
\hline Past 211 (98.1) 4 (1.9) 0.068 \\
\hline Never 3503 (97.1) 106 (2.9) \\
\hline
\end{tabular}

\subsection{Multivariate analysis of factors associated with hypomagnesemia}

We performed multivariate logistic regression to identify the factors related to hypomagnesaemia after controlling for age. Table 6 shows the association of low magnesium status with metabolic syndrome after adjusting for age. We found that metabolic syndrome patients were 1.57 times more likely to have 
hypomagnesemia as compared to those without the condition $(p=0.048)$. participants who were 60 years or more were 2.73 times more likely to have hypomagnesemia compared to younger age groups ( $p$ $=0.007)$.

\section{Table 6}

Factors related to hypomagnesemia among the study participants using multivariate logistic regression, Jordan 2009

\begin{tabular}{|l|}
\hline Variable Serum magnesium levels, $\mathrm{mg} / \mathrm{dl}$ \\
$>1.82<=1.82 \mathrm{P}$ value \\
No. (\%) No. (\%) \\
\hline Total 4400 (97.3) 120 (2.7) \\
Metabolic syndrome (IDF) \\
Yes 1382 (95.7) 62 (4.3) \\
No 2139 (98.0) 44 (2.0) 0.000 \\
Central obesity (Waist circumference $\geq 80 \mathrm{~cm}$ for women $\& \geq 94 \mathrm{~cm}$ for men) \\
Yes 2644 (97.2) 76 (2.8) \\
No 1593 (98.1) 31 (1.9) 0.041 \\
Elevated triglycerides (Triglycerides $\geq 150 \mathrm{mg} / \mathrm{dl}$ or specific treatment for lipid abnormality) \\
Yes 2174 (97.8) 50 (2.2) \\
No 2226 (97.0) 70 (3.0) 0.057 \\
Low HDL (HDL-C< 40 mg/dl in men and < $50 \mathrm{mg} / \mathrm{dl}$ in women) \\
Yes 2863 (96.7) 97 (3.3) \\
No 1537 (98.5) 23 (1.5) 0.000 \\
Hypertension (Blood pressure $\geq 130 / 85 \mathrm{mmHg}$ or drug treatment for hypertension) \\
Yes 1781 (96.4) 66 (3.6) \\
No 2605 (98.0) 54 (2.0) 0.001 \\
Hyperglycemia (Blood glucose greater than $100 \mathrm{mg} / \mathrm{dl}$ or treatment for diabetes) \\
Yes 936 (94.9) 50 (5.1) \\
No 2271 (97.1) 69 (2.9) 0.002 \\
\hline
\end{tabular}

Table 7 shows the association of low magnesium status with metabolic syndrome components after adjusting for age only. In the bivariate analysis, hypomagnesemia was significantly associated with central obesity, low HDL, hypertension, and hyperglycemia. After using multivariate logistic regression, the only variable that remains statistically significant was low HDL. We found that participants with low HDL 
were 2.15 more likely to have hypomagnesemia in comparison to those with normal HDL levels $(p=$ 0.001). Interestingly, hypomagnesemia was found to be statistically significant with high triglycerides levels. People with high levels of triglycerides were $60 \%$ less likely to develop hypomagnesemia compared to those with normal triglycerides levels $(p=0.010)$. 
Table 7

Metabolic syndrome components in relation to hypomagnesemia among the study participants using multivariate logistic regression, Jordan 2009

\begin{tabular}{|l|}
\hline Variable Odds Ratio P value \\
\hline Metabolic syndrome (IDF) \\
No 1 \\
\hline Yes 1.570 .048 \\
\hline Age (years) \\
\hline $20-291$ \\
\hline $30-391.060 .862$ \\
\hline $50-591.900 .088$ \\
$\geq 602.730 .007$ \\
Variable 0 dds Ratio* P value \\
\hline Central obesity (Waist circumference $\geq 80 \mathrm{~cm}$ for women $\& \geq 94 \mathrm{~cm}$ for men) \\
\hline No 1 \\
Yes 1.120 .621 \\
\hline Elevated triglycerides $(\geq 150 \mathrm{mg} / \mathrm{dl}$ or specific treatment for lipid abnormality) \\
\hline No 1 \\
Yes 0.600 .010 \\
\hline Low HDL (HDL-C< 40 mg/dl in men and $<50$ mg/dl in women) \\
\hline No 1 \\
Yes 2.150 .001 \\
\hline Hypertension ((Blood pressure $\geq 130 / 85 \mathrm{mmHg}$ or drug treatment for hypertension) \\
\hline No 1 \\
Yes 1.370 .140 \\
\hline Hyperglycemia ((Blood glucose greater than 100 mg/dl or treatment for diabetes) \\
\hline No 1 \\
\hline *Each of these variables in this table was adjusted for age only \\
\hline
\end{tabular}


In linear regression models, we also found an inverse association between magnesium and metabolic syndrome and low HDL when magnesium was analyzed as a continuous variable.

\section{Discussion}

In this national population-based study conducted in Jordan in 2009, we demonstrated the prevalence of metabolic syndrome and its components among adults and their relation to low magnesium levels. We found alarmingly high prevalence rates of metabolic syndrome and its components as defined by IDF criteria. Indeed, more than one-third of all Jordanian adults met the criteria of metabolic syndrome (39.8\%), with the highest burden being among women (40.7\% in women and $37.4 \%$ in men). Among metabolic syndrome components, central obesity and low HDL were the most commonly occurring components of metabolic syndrome ( $62.6 \%$ and $65.5 \%$, respectively). In fact, central obesity was more prevalent among women (66.5\%), while low HDL was more prevalent among men (69.6\%). These findings are consistent with the study conducted in Northern Jordan, using ATP definition, which reported a metabolic syndrome prevalence estimate of $36.3 \%$, being higher in women than in men $(40.9 \%$ and $28.7 \%$, respectively). Furthermore, this study found that central obesity was the most common abnormality in women (69.1\%), while low HDL was the most common abnormality in men (62.7\%) (24). Interestingly, using IDF criteria, the prevalence of metabolic syndrome in Jordan was markedly higher in 2017 being $48.2 \%$ (52.9\% in men and $46.2 \%$ in women) (25).

Our metabolic syndrome prevalence estimate was slightly higher than those reported in the US population from 2003-2012 (33.0\%) (26) and Australian population (35.8\%) (27). On the other hand, higher estimates were reported in Turkey (44.0\%), Pakistan (63.7\%), Tunisia (45.5\%), and Emirates (48.7\%) (28). The considerable variations in the prevalence rates of metabolic syndrome may be attributable to many factors, including the criteria of metabolic syndrome used, study design and sampling, the variations in age and gender structure of the population, and a combination of genetics and environmental factors.

Our results showed high rates of abdominal obesity (62.6\%). This is in line with the studies conducted among the US and Greek population with abdominal obesity rates of $53 \%$ and $72 \%$, respectively $(29,30)$. Interestingly, counties with high rates of metabolic syndrome demonstrated high rates of central obesity; Portugal (51.0\%)(31), Turkey (56.8\%)(32), Tunisia (69.5\%)(33). consequently, the high prevalence of metabolic syndrome could be explained by the high prevalence of abdominal obesity. Obesity is a worldwide health problem being attributable to the increased risk of several diseases, including diabetes and cardiovascular diseases (34). It has been proposed that by 2030 , obesity will reach levels of $89 \%$ and $85 \%$ in males and females, respectively (35). Therefore, the implementation of health care programs is strongly recommended to increase people's awareness towards an adoption of a healthy lifestyle in the form of appropriate dietary habits and physical activity.

Magnesium deficiency may play an essential role in the development of metabolic syndrome. In line with this, our results revealed an independent relationship between metabolic syndrome and low serum magnesium levels. The inverse association found in the present study is supported by findings of various 
other studies (14-16, 36-40). Furthermore, studies have demonstrated that metabolic syndrome is less prevalent in subjects with higher levels of dietary magnesium intake (41-46). In this context, results from these studies support the hypothesis that low body magnesium status could be a potential risk factor for the development of metabolic syndrome. The present finding is not consistent, however, with the results from cross-sectional studies which revealed no association between serum magnesium and metabolic syndrome $(17,43)$. No association was also found between dietary magnesium intake and supplementation with metabolic syndrome in prospective and clinical randomized studies, respectively $(47,48)$. Additionally, hair magnesium concentration was shown to have no significant association with metabolic syndrome (19). The discrepancy between the results of the studies could be explained by differences in the sample size, variability in the characteristics of the study populations, and the geographical locations where there are differences in the lifestyle, dietary habits, and genetic phenotype among individuals. In fact, populations may have different responses to the same level of magnesium depending on the variations in genetic background (16). Interestingly, the use of different criteria for metabolic syndrome could affect the association. Indeed, a meta-analysis study found that the association was stronger in studies that used the NCEP-ATP III definition rather than the modified NCEPATP III, IDF, AHA/NHLBI, or WHO definitions (16). Furthermore, hair analysis is considered to be an unreliable tool for assessing trace elements and nutritional balance in individuals (49).

The relationship between serum magnesium levels and components of the metabolic syndrome is conflicting. Our study suggests an independent association between hypomagnesemia and decreased levels of HDL-cholesterol. Our finding is in agreement with the study conducted by Guerrero-Romero concluding that hypomagnesemia contributed to lower HDL (13). A case-control study of low serum magnesium level and lipid profile among patients with osteoarthritis, found that hypomagnesemia was related to decreased serum levels of HDL $(p<0.001)(50)$. Findings suggest that low serum magnesium levels could be incriminated in the pathogenesis of cardiovascular disease through alteration in the blood lipid composition in a way that predisposes to atherosclerosis (51). One possible explanation is that magnesium acts as a cofactor for a number of enzymes involved in lipid metabolism. Indeed, it has been postulated that magnesium intake may increase the activity of lipoprotein lipase, which is involved in the conversion of triglycerides to HDL-Cholesterol (52).

Our results revealed no significant association between low magnesium levels and central obesity. This finding is in accordance with the previous reports (53-55). In fact, it has been shown that middle-aged obese individuals can maintain normal circulating levels of magnesium, compared to type 2 diabetes and older subjects (56). We have also failed to demonstrate a cross-sectional relationship between low serum magnesium levels and hyperglycemia. Our results are supported by a 12-week clinical randomized study concluding that magnesium replacement in recommended dosage didn't reduce insulin resistance (48). Finally, our study showed that individuals with hypertension had lower levels of serum magnesium with respect to those with normal blood pressure, but this association was no longer significant in multivariate analysis. 
Although our study has the strength of being a national population-based study with a relatively large sample size, there are several limitations that deserve to be mentioned. First, since the study was crosssectional in nature, a temporal relationship between hypomagnesemia and metabolic syndrome can't be established, and thus we don't know whether low magnesium concentration was a consequence of metabolic syndrome or a precipitating factor leading to its development. Second, the dietary intake of magnesium in relation to the prevalence of metabolic syndrome and its components was not assessed in the present study. Last but not least, we have used serum magnesium to indicate low magnesium status. It is important to highlight the fact that magnesium is chiefly an intracellular ion; therefore, serum magnesium is considered to be a poor indicator of body magnesium. However, serum magnesium is the most widely used measure of magnesium status in many studies to illustrate the relationship between magnesium and metabolic syndrome.

In conclusion, the prevalence of metabolic syndrome is considerably high in Jordan accounting for more than one-third of all Jordanian adults. Central obesity and low HDL were the most occurring components of metabolic syndrome. The increase in the prevalence of metabolic syndrome and its components is probably due to the adoption of westernized behaviors and sedentary life-style. Therefore, future policies and health education programs, aiming at encouraging people to adhere to the guidelines and recommendations of a healthy diet and physical activity, should be taken into consideration. Furthermore, the findings from the present study provide evidence that serum magnesium is inversely associated with the prevalence of metabolic syndrome. However, the data cannot support a causal role for hypomagnesemia in the development of metabolic syndrome because of the cross-sectional nature of the study.

\section{Declarations}

Conflicts of Interest: The authors declare no conflict of interest.

\section{References}

1. Global, regional, and national age-sex specific mortality for 264 causes of death, 1980-2016: a systematic analysis for the Global Burden of Disease Study 2016. Lancet (London, England). 2017;390(10100):1151-210.

2. Mozaffarian D, Afshin A, Benowitz NL, Bittner V, Daniels SR, Franch HA, et al. Population approaches to improve diet, physical activity, and smoking habits: a scientific statement from the American Heart Association. Circulation. 2012;126(12):1514-63.

3. Ford ES. Risks for all-cause mortality, cardiovascular disease, and diabetes associated with the metabolic syndrome: a summary of the evidence. Diabetes care. 2005;28(7):1769-78.

4. O'Neill S, O'Driscoll L. Metabolic syndrome: a closer look at the growing epidemic and its associated pathologies. Obesity reviews : an official journal of the International Association for the Study of Obesity. 2015;16(1):1-12. 
5. Srikanthan K, Feyh A, Visweshwar H, Shapiro JI, Sodhi K. Systematic Review of Metabolic Syndrome Biomarkers: A Panel for Early Detection, Management, and Risk Stratification in the West Virginian Population. International journal of medical sciences. 2016;13(1):25-38.

6. Laakso M, Kuusisto J. Insulin resistance and hyperglycaemia in cardiovascular disease development. Nature reviews Endocrinology. 2014;10(5):293-302.

7. Martin KJ, González EA, Slatopolsky E. Clinical consequences and management of hypomagnesemia. Journal of the American Society of Nephrology : JASN. 2009;20(11):2291-5.

8. Gröber U, Schmidt J, Kisters K. Magnesium in Prevention and Therapy. Nutrients. 2015;7(9):8199226.

9. Jahnen-Dechent W, Ketteler M. Magnesium basics. Clinical Kidney Journal. 2012;5(Suppl_1):i3-i14.

10. de Baaij JH, Hoenderop JG, Bindels RJ. Regulation of magnesium balance: lessons learned from human genetic disease. Clin Kidney J. 2012;5(Suppl 1):i15-i24.

11. Joy SS, George TP, Siddiqui K. Low magnesium level as an indicator of poor glycemic control in type 2 diabetic patients with complications. Diabetes \& metabolic syndrome. 2019;13(2):1303-7.

12. Zohal M, Jam-Ashkezari S, Namiranian N, Moosavi A, Ghadiri-Anari A. Association between selected trace elements and body mass index and waist circumference: A cross sectional study. Diabetes \& metabolic syndrome. 2019;13(2):1293-7.

13. Guerrero-Romero F, Rodríguez-Morán M. Hypomagnesemia is linked to low serum HDL-cholesterol irrespective of serum glucose values. Journal of diabetes and its complications. 2000;14(5):272-6.

14. Guerrero-Romero F, Rodríguez-Morán M. Low serum magnesium levels and metabolic syndrome. Acta diabetologica. 2002;39(4):209-13.

15. Ghasemi A, Zahediasl S, Syedmoradi L, Azizi F. Low serum magnesium levels in elderly subjects with metabolic syndrome. Biological trace element research. 2010;136(1):18-25.

16. La SA, Lee JY, Kim DH, Song EL, Park JH, Ju SY. Low Magnesium Levels in Adults with Metabolic Syndrome: a Meta-Analysis. 2016;170(1):33-42.

17. Park SH, Kim SK, Bae YJ. Relationship between serum calcium and magnesium concentrations and metabolic syndrome diagnostic components in middle-aged Korean men. Biological trace element research. 2012;146(1):35-41.

18. Kim HN, Kim SH, Eun YM, Song SW. Effects of zinc, magnesium, and chromium supplementation on cardiometabolic risk in adults with metabolic syndrome: A double-blind, placebo-controlled randomised trial. Journal of trace elements in medicine and biology : organ of the Society for Minerals and Trace Elements (GMS). 2018;48:166-71.

19. Chung JH, Yum KS. Correlation of hair mineral concentrations with insulin resistance in Korean males. Biological trace element research. 2012;150(1-3):26-30.

20. Yu Y, Cai Z, Zheng J, Chen J, Zhang X, Huang XF, et al. Serum levels of polyunsaturated fatty acids are low in Chinese men with metabolic syndrome, whereas serum levels of saturated fatty acids, zinc, and magnesium are high. Nutrition research (New York, NY). 2012;32(2):71-7. 
21. Batieha A, Khader Y, Jaddou H, Hyassat D, Batieha Z, Khateeb M, et al. Vitamin D status in Jordan: dress style and gender discrepancies. Annals of nutrition \& metabolism. 2011;58(1):10-8.

22. Alberti KG, Zimmet P, Shaw J. Metabolic syndrome--a new world-wide definition. A Consensus Statement from the International Diabetes Federation. Diabetic medicine : a journal of the British Diabetic Association. 2006;23(5):469-80.

23. Lowenstein FW, Stanton MF. Serum magnesium levels in the United States, 1971-1974. Journal of the American College of Nutrition. 1986;5(4):399-414.

24. Khader Y, Bateiha A, El-Khateeb M, Al-Shaikh A, Ajlouni K. High prevalence of the metabolic syndrome among Northern Jordanians. Journal of diabetes and its complications. 2007;21(4):214-9.

25. Ajlouni K, Khader Y. Metabolic syndrome amongst adults in Jordan: prevalence, trend, and its association with socio-demographic characteristics. 2020;12(1):100.

26. Aguilar M, Bhuket T, Torres S, Liu B, Wong RJ. Prevalence of the metabolic syndrome in the United States, 2003-2012. Jama. 2015;313(19):1973-4.

27. Vaughan C, Schoo A, Janus ED, Philpot B, Davis-Lameloise N, Lo SK, et al. The association of levels of physical activity with metabolic syndrome in rural Australian adults. BMC public health. 2009;9:273.

28. Ansarimoghaddam A, Adineh HA, Zareban I, Iranpour S, HosseinZadeh A, Kh F. Prevalence of metabolic syndrome in Middle-East countries: Meta-analysis of cross-sectional studies. Diabetes \& metabolic syndrome. 2018;12(2):195-201.

29. Ervin RB. Prevalence of metabolic syndrome among adults 20 years of age and over, by sex, age, race and ethnicity, and body mass index: United States, 2003-2006. National health statistics reports. 2009(13):1-7.

30. Athyros VG, Bouloukos VI, Pehlivanidis AN, Papageorgiou AA, Dionysopoulou SG, Symeonidis AN, et al. The prevalence of the metabolic syndrome in Greece: the MetS-Greece Multicentre Study. Diabetes, obesity \& metabolism. 2005;7(4):397-405.

31. Raposo L, Severo M, Barros H, Santos AC. The prevalence of the metabolic syndrome in Portugal: the PORMETS study. BMC public health. 2017;17(1):555.

32. Gündogan K, Bayram F, Capak M, Tanriverdi F, Karaman A, Ozturk A, et al. Prevalence of metabolic syndrome in the Mediterranean region of Turkey: evaluation of hypertension, diabetes mellitus, obesity, and dyslipidemia. Metabolic syndrome and related disorders. 2009;7(5):427-34.

33. Harzallah F, Alberti H, Ben Khalifa F. The metabolic syndrome in an Arab population: a first look at the new International Diabetes Federation criteria. Diabetic medicine : a journal of the British Diabetic Association. 2006;23(4):441-4.

34. Wang YC, McPherson K, Marsh T, Gortmaker SL, Brown M. Health and economic burden of the projected obesity trends in the USA and the UK. The Lancet. 2011;378(9793):815-25.

35. Keaver L, Webber L, Dee A, Shiely F, Marsh T, Balanda K, et al. Application of the UK foresight obesity model in Ireland: the health and economic consequences of projected obesity trends in Ireland. PloS one. 2013;8(11):e79827. 
36. Rotter I, Kosik-Bogacka D, Dołęgowska B, Safranow K, Karakiewicz B, Laszczyńska M. Relationship between serum magnesium concentration and metabolic and hormonal disorders in middle-aged and older men. Magnesium research. 2015;28(3):99-107.

37. Rotter I, Kosik-Bogacka D, Dołęgowska B, Safranow K, Lubkowska A, Laszczyńska M. Relationship between the concentrations of heavy metals and bioelements in aging men with metabolic syndrome. International journal of environmental research and public health. 2015;12(4):3944-61.

38. Lima Mde L, Cruz T, Rodrigues LE, Bomfim O, Melo J, Correia R, et al. Serum and intracellular magnesium deficiency in patients with metabolic syndrome--evidences for its relation to insulin resistance. Diabetes research and clinical practice. 2009;83(2):257-62.

39. Wang Y, Wei J, Zeng C, Yang T, Li H, Cui Y, et al. Association between serum magnesium concentration and metabolic syndrome, diabetes, hypertension and hyperuricaemia in knee osteoarthritis: a cross-sectional study in Hunan Province, China. BMJ open. 2018;8(9):e019159.

40. Evangelopoulos AA, Vallianou NG, Panagiotakos DB, Georgiou A, Zacharias GA, Alevra AN, et al. An inverse relationship between cumulating components of the metabolic syndrome and serum magnesium levels. Nutrition research (New York, NY). 2008;28(10):659-63.

41. Song Y, Ridker PM, Manson JE, Cook NR, Buring JE, Liu S. Magnesium intake, C-reactive protein, and the prevalence of metabolic syndrome in middle-aged and older U.S. women. Diabetes care. 2005;28(6):1438-44.

42. Ford ES, Li C, McGuire LC, Mokdad AH, Liu S. Intake of dietary magnesium and the prevalence of the metabolic syndrome among U.S. adults. Obesity (Silver Spring, Md). 2007;15(5):1139-46.

43. Huang JH, Lu YF, Cheng FC, Lee JN, Tsai LC. Correlation of magnesium intake with metabolic parameters, depression and physical activity in elderly type 2 diabetes patients: a cross-sectional study. Nutrition journal. 2012;11:41.

44. Dibaba DT, Xun P, Fly AD, Yokota K, He K. Dietary magnesium intake and risk of metabolic syndrome: a meta-analysis. Diabetic medicine : a journal of the British Diabetic Association. 2014;31(11):13019.

45. Sarrafzadegan N, Khosravi-Boroujeni H, Lotfizadeh M, Pourmogaddas A, Salehi-Abargouei A. Magnesium status and the metabolic syndrome: A systematic review and meta-analysis. Nutrition (Burbank, Los Angeles County, Calif). 2016;32(4):409-17.

46. He K, Liu K, Daviglus ML, Morris SJ, Loria CM, Van Horn L, et al. Magnesium intake and incidence of metabolic syndrome among young adults. Circulation. 2006;113(13):1675-82.

47. Noori N, Nafar M, Poorrezagholi F, Ahmadpoor P, Samadian F, Firouzan A, et al. Dietary intakes of fiber and magnesium and incidence of metabolic syndrome in first year after renal transplantation. Journal of renal nutrition : the official journal of the Council on Renal Nutrition of the National Kidney Foundation. 2010;20(2):101-11.

48. Lima de Souza ESML, Cruz T, Rodrigues LE, Ladeia AM, Bomfim O, Olivieri L, et al. Magnesium replacement does not improve insulin resistance in patients with metabolic syndrome: a 12-week randomized double-blind study. Journal of clinical medicine research. 2014;6(6):456-62. 
49. Seidel S, Kreutzer R, Smith D, McNeel S, Gilliss D. Assessment of commercial laboratories performing hair mineral analysis. Jama. 2001;285(1):67-72.

50. Chavan VU, Ramavataram D, Patel PA, Rupani MP. Evaluation of serum magnesium, lipid profile and various biochemical parameters as risk factors of cardiovascular diseases in patients with rheumatoid arthritis. Journal of clinical and diagnostic research : JCDR. 2015;9(4):Bc01-5.

51. Rasmussen HS, Aurup P, Goldstein K, McNair P, Mortensen PB, Larsen OG, et al. Influence of magnesium substitution therapy on blood lipid composition in patients with ischemic heart disease. A double-blind, placebo controlled study. Archives of internal medicine. 1989;149(5):1050-3.

52. Rayssiguier $Y$, Gueux E, Weiser D. Effect of magnesium deficiency on lipid metabolism in rats fed a high carbohydrate diet. The Journal of nutrition. 1981;111(11):1876-83.

53. Simmons D, Joshi S, Shaw J. Hypomagnesaemia is associated with diabetes: Not pre-diabetes, obesity or the metabolic syndrome. Diabetes research and clinical practice. 2010;87(2):261-6.

54. Morais JBS, de Freitas TEC, Severo JS, de Oliveira ARS, Cruz KJC, de Almendra Freitas B, et al. No Difference in Magnesium Intake between Obese Women and Healthy Controls. International journal for vitamin and nutrition research Internationale Zeitschrift fur Vitamin- und Ernahrungsforschung Journal international de vitaminologie et de nutrition. 2019;89(3-4):118-24.

55. Toprak O, Kurt H, Sarı Y, Şarkış C, Us H, Kırık A. Magnesium Replacement Improves the Metabolic Profile in Obese and Pre-Diabetic Patients with Mild-to-Moderate Chronic Kidney Disease: A 3-Month, Randomised, Double-Blind, Placebo-Controlled Study. Kidney \& blood pressure research. 2017;42(1):33-42.

56. De Leeuw I, Vansant G, Van Gaal L. Magnesium and obesity: influence of gender, glucose tolerance, and body fat distribution on circulating magnesium concentrations. Magnesium research. 1992;5(3):183-7.

\section{Tables}


Table 1: Sociodemographic characteristics of the study participants $(\mathrm{N}=4520)$, Jordan 2009

\begin{tabular}{|lc|}
\hline Variable & NO.(\%) \\
\hline Age (year) & $827(18.3)$ \\
$30-29$ & $1202(26.6)$ \\
$40-49$ & $1237(27.8)$ \\
$50-59$ & $702(15.5)$ \\
$\geq 60$ & $502(12.2)$ \\
\hline Gender & \\
\hline Men & $1113(24.6)$ \\
Women & $3407(75.4)$ \\
\hline Marital status & $585(12.9)$ \\
\hline Single & $3613(79.9)$ \\
Married & $67(1.5)$ \\
Divorced & $255(5.6)$ \\
Widow & $684(15.1)$ \\
\hline Smoking status & $215(4.8)$ \\
\hline Current & $4609(79.9)$ \\
Past & \\
Never & \\
\hline
\end{tabular}

Table 2: Anthropometric and clinical characteristics of the study participants $(\mathrm{N}=4520)$, Jordan 2009

\begin{tabular}{|lc|}
\hline Variable & Mean (SD) \\
\hline Body mass index $\left(\mathrm{kg} / \mathrm{m}^{2}\right)$ & $29.9(5.9)$ \\
Waist circumference $(\mathrm{cm})$ & $87.6(14.5)$ \\
Systolic blood pressure $(\underline{\mathrm{mmHg}})$ & $122.4(17.3)$ \\
Diastolic blood pressure (mmHg) & $79.0(10.3)$ \\
Fasting blood sugar $(\mathrm{mg} / \mathrm{dl})$ & $102.6(50.6)$ \\
HDL $(\mathrm{mg} / \mathrm{dl})$ & $43.9(13.6)$ \\
Triglyceride $(\mathrm{mg} / \mathrm{dl})$ & $175.9(123.5)$ \\
Serum magnesium $(\mathrm{mg} / \mathrm{dl})$ & $2.4(0.4)$ \\
\hline
\end{tabular}


Table 3: The gender-specific rates of metabolic syndrome and its individualized components in Jordan, using the IDF definition, Jordan 2009

\begin{tabular}{|c|c|c|c|c|}
\hline Variable & $\begin{array}{l}\text { Men } \\
\text { No. }(\%)\end{array}$ & $\begin{array}{l}\text { Women } \\
\text { No. }(\%)\end{array}$ & $\begin{array}{l}\text { Total } \\
\text { No. }(\%)\end{array}$ & P value \\
\hline \multicolumn{5}{|c|}{ Metabolic syndrome (IDF) } \\
\hline Yes & $354(37.4)$ & $1090(40.7)$ & $1444(39.8)$ & \\
\hline No & $593(62.6)$ & $1590(59.3)$ & $2183(60.2)$ & 0.041 \\
\hline \multicolumn{5}{|c|}{ Central obesity (Waist circumference $\geq 80 \mathrm{~cm}$ for women $\& \geq 94 \mathrm{~cm}$ for men) } \\
\hline Yes & $569(51.3)$ & $2151(66.5)$ & $2720(62.6)$ & \\
\hline No & $541(48.7)$ & $1083(33.5)$ & $1624(37.4)$ & 0.000 \\
\hline \multicolumn{5}{|c|}{$\begin{array}{l}\text { Elevated Triglycerides (Triglycerides } \geq 150 \mathrm{mg} / \mathrm{dl} \text { or specific treatment for lipid } \\
\text { abnormality) }\end{array}$} \\
\hline Yes & $701(63.0)$ & $1523(44.7)$ & $2224(49.2)$ & \\
\hline No & $412(37.0)$ & $1884(55.3)$ & $2296(50.8)$ & 0.000 \\
\hline \multicolumn{5}{|c|}{ Low HDL (HDL-C $<40 \mathrm{mg} / \mathrm{dl}$ in men and $<50 \mathrm{mg} / \mathrm{dl}$ in women) } \\
\hline Yes & $778(69.6)$ & $2182(64.0)$ & $2960(65.5)$ & \\
\hline No & $335(30.1)$ & $1225(36.0)$ & $1560(34.5)$ & 0.000 \\
\hline \multicolumn{5}{|c|}{ Hypertension (Blood pressure $\geq \mathbf{1 3 0 / 8 5} \mathbf{~ m m H g}$ or drug treatment for hypertension) } \\
\hline Yes & $589(53.1)$ & $1258(37.0)$ & $1847(41.0)$ & \\
\hline No & $521(46.9)$ & $2138(63.0)$ & $2659(59.0)$ & 0.000 \\
\hline \multicolumn{5}{|c|}{ Hyperglycemia (Blood glucose greater than $100 \mathrm{mg} / \mathrm{dl}$ or treatment for diabetes) } \\
\hline Yes & $313(38.4)$ & $673(26.8)$ & $986(29.6)$ & \\
\hline No & $502(61.6)$ & $1838(73.2)$ & $2340(70.4)$ & 0.000 \\
\hline
\end{tabular}


Table 4: Prevalence of hypomagnesemia, overall and by Sociodemographic characteristics of the study participants, Jordan 2009

\begin{tabular}{|c|c|c|c|}
\hline Variable & $\begin{array}{l}\text { Serum magl } \\
>1.82 \\
\text { No. }(\%)\end{array}$ & $\begin{array}{l}\text { els, mg/dl } \\
<=1.82 \\
\text { No. }(\%)\end{array}$ & $P$ value \\
\hline Total & $4400(97.3)$ & $120(2.7)$ & \\
\hline \multicolumn{4}{|c|}{ Age (years) } \\
\hline $20-29$ & $809(97.8)$ & $18(2.2)$ & \multirow{5}{*}{0.000} \\
\hline $30-39$ & 1174 (97.9) & $28(2.3)$ & \\
\hline $40-49$ & $1220(98.6)$ & $17(1.4)$ & \\
\hline $50-59$ & $675(96.6)$ & $27(3.8)$ & \\
\hline$\geq 60$ & $522(94.6)$ & $30(5.4)$ & \\
\hline \multicolumn{4}{|l|}{ Gender } \\
\hline Men & $1091(98.0)$ & $22(2.0)$ & \multirow[b]{2}{*}{0.062} \\
\hline Women & $3309(97.1)$ & $98(2.9)$ & \\
\hline \multicolumn{4}{|c|}{ Marital status } \\
\hline Single & $574(98.1)$ & $11(1.9)$ & \multirow{4}{*}{0.055} \\
\hline Married & $3518(97.4)$ & $95(2.6)$ & \\
\hline Divorced & $66(95.5)$ & $1(1.5)$ & \\
\hline Widow & 242 (94.9) & $13(5.1)$ & \\
\hline \multicolumn{4}{|c|}{ Smoking status } \\
\hline Current & $674(98.5)$ & $10(1.5)$ & \multirow{3}{*}{0.068} \\
\hline Past & $211(98.1)$ & $4(1.9)$ & \\
\hline Never & $3503(97.1)$ & $106(2.9)$ & \\
\hline
\end{tabular}


Table 5: Prevalence of hypomagnesemia by metabolic syndrome and its individualized components, using IDF definition, Jordan 2009

\begin{tabular}{|c|c|c|c|}
\hline Variable & $\begin{array}{l}\text { Serum magne } \\
>1.82 \\
\text { No. }(\%)\end{array}$ & $\begin{array}{l}\text { els, mg/dl } \\
<=1.82 \\
\text { No. }(\%)\end{array}$ & $P$ value \\
\hline Total & $4400(97.3)$ & $120(2.7)$ & \\
\hline \multicolumn{4}{|c|}{ Metabolic syndrome (IDF) } \\
\hline Yes & $1382(95.7)$ & $62(4.3)$ & \\
\hline No & $2139(98.0)$ & $44(2.0)$ & 0.000 \\
\hline \multicolumn{4}{|c|}{ Central obesity (Waist circumference $\geq 80 \mathrm{~cm}$ for women $\& \geq 94 \mathrm{~cm}$ for men) } \\
\hline Yes & $2644(97.2)$ & $76(2.8)$ & \\
\hline No & $1593(98.1)$ & $31(1.9)$ & 0.041 \\
\hline \multicolumn{4}{|c|}{$\begin{array}{l}\text { Elevated triglycerides (Triglycerides } \geq 150 \mathrm{mg} / \mathrm{dl} \text { or specific treatment for lipid } \\
\text { abnormality) }\end{array}$} \\
\hline Yes & $2174(97.8)$ & $50(2.2)$ & \\
\hline No & $2226(97.0)$ & $70(3.0)$ & 0.057 \\
\hline \multicolumn{4}{|c|}{ Low HDL (HDL-C $<40 \mathrm{mg} / \mathrm{dl}$ in men and $<50 \mathrm{mg} / \mathrm{dl}$ in women) } \\
\hline Yes & $2863(96.7)$ & $97(3.3)$ & \\
\hline No & $1537(98.5)$ & $23(1.5)$ & 0.000 \\
\hline \multicolumn{4}{|c|}{ Hypertension (Blood pressure $\geq \mathbf{1 3 0 / 8 5} \mathbf{m m H g}$ or drug treatment for hypertension) } \\
\hline Yes & $1781(96.4)$ & $66(3.6)$ & \\
\hline No & $2605(98.0)$ & $54(2.0)$ & 0.001 \\
\hline \multicolumn{4}{|c|}{ Hyperglycemia (Blood glucose greater than $100 \mathrm{mg} / \mathrm{dl}$ or treatment for diabetes) } \\
\hline Yes & $936(94.9)$ & $50(5.1)$ & \\
\hline No & $2271(97.1)$ & $69(2.9)$ & 0.002 \\
\hline
\end{tabular}

Table 6: Factors related to hypomagnesemia among the study participants using multivariate logistic regression, Jordan 2009

\begin{tabular}{|lcc|}
\hline Variable & Odds Ratio & P value \\
\hline Metabolic syndrome (IDF) & 1 & \\
\hline No & 1.57 & 0.048 \\
Yes & & \\
\hline Age (years) & 1 & \\
\hline $20-29$ & 1.06 & 0.862 \\
$30-39$ & 0.77 & 0.512 \\
$40-49$ & 1.90 & 0.088 \\
$50-59$ & 2.73 & 0.007 \\
$\geq 60$ & & \\
\hline
\end{tabular}


Table 7: Metabolic syndrome components in relation to hypomagnesemia among the study participants using multivariate logistic regression, Jordan 2009

\begin{tabular}{|c|c|c|}
\hline Variable & Odds Ratio* & P value \\
\hline \multicolumn{3}{|c|}{ Central obesity (Waist circumference $\geq 80 \mathrm{~cm}$ for women $\& \geq 94 \mathrm{~cm}$ for men) } \\
\hline No & 1 & \\
\hline Yes & 1.12 & 0.621 \\
\hline \multicolumn{3}{|c|}{ Elevated triglycerides $(\geq 150 \mathrm{mg} / \mathrm{dl}$ or specific treatment for lipid abnormality) } \\
\hline No & 1 & \\
\hline Yes & 0.60 & 0.010 \\
\hline \multicolumn{3}{|c|}{ Low HDL (HDL-C $<40$ mg/dl in men and $<50 \mathrm{mg} / \mathrm{dl}$ in women) } \\
\hline No & 1 & \\
\hline Yes & 2.15 & 0.001 \\
\hline \multicolumn{3}{|c|}{ Hypertension ((Blood pressure $\geq 130 / 85 \mathrm{mmHg}$ or drug treatment for hypertension) } \\
\hline No & 1 & \\
\hline Yes & 1.37 & 0.140 \\
\hline \multicolumn{3}{|c|}{ Hyperglycemia ((Blood glucose greater than $100 \mathrm{mg} / \mathrm{dl}$ or treatment for diabetes) } \\
\hline No & 1 & \\
\hline Yes & 1.43 & 0.091 \\
\hline
\end{tabular}

*Each of these variables in this table was adjusted for age only

\section{Supplementary Files}

This is a list of supplementary files associated with this preprint. Click to download.

- Authors.docx 